\title{
Lives in Translation
}

Arthur M. Feldman, MD, PhD, Editor-IN-Chief, CTS

T his past year marked the untimely deaths of two friends and colleagues who had both made life-long contributions to the field of translational medicine: Dr. Kenneth L. Baughman of the Shapiro Cardiovascular Institute of the Brigham and Women's Hospital in Boston and Dr. Merrill J. Egorin of the University of Pittsburgh Cancer Center. As I thought about their lives and their work, I was struck by the fact that each had come to the field of translational medicine from a very different direction and perspective, yet they shared an unabiding belief in the importance of educating the next generation and in the delivery of excellent patient care.

A native of Baltimore, Merrill Egorin was an undergraduate medical student, medical resident, and oncology fellow at Johns Hopkins. After several years on the Hopkins faculty, he moved his laboratory to the Baltimore Cancer Research Center at the University of Maryland and later to the University of Pittsburgh where he served as co-leader of the institute's Molecular Therapeutics and Drug Discovery Program and director of its Clinical Pharmacology Analytical Facility. Merrill was the consummate clinician-scientist. With his first publication in 1973, he began what would be a 37-year scientific career, studying the pharmacokinetics, metabolism, therapeutic efficacy, and toxicity of drugs that were being developed for the treatment of cancer. Known

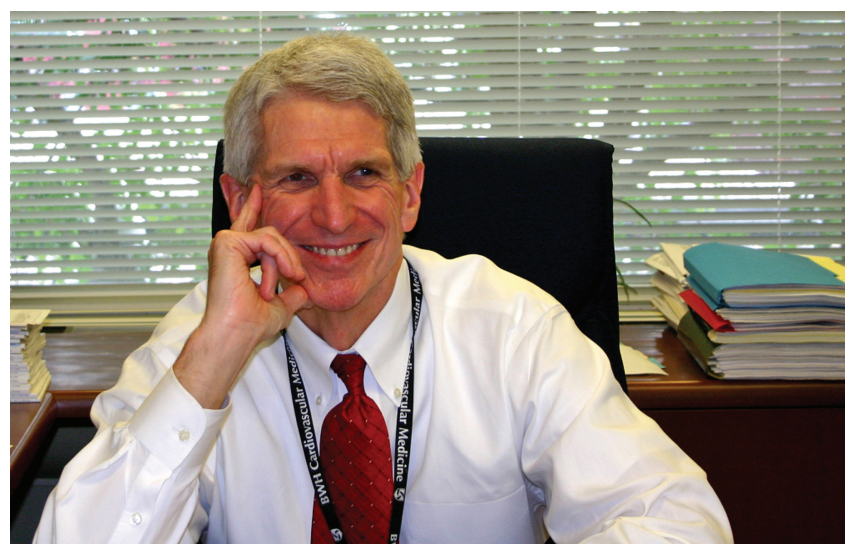

Kenneth L. Baughman 1946-2009

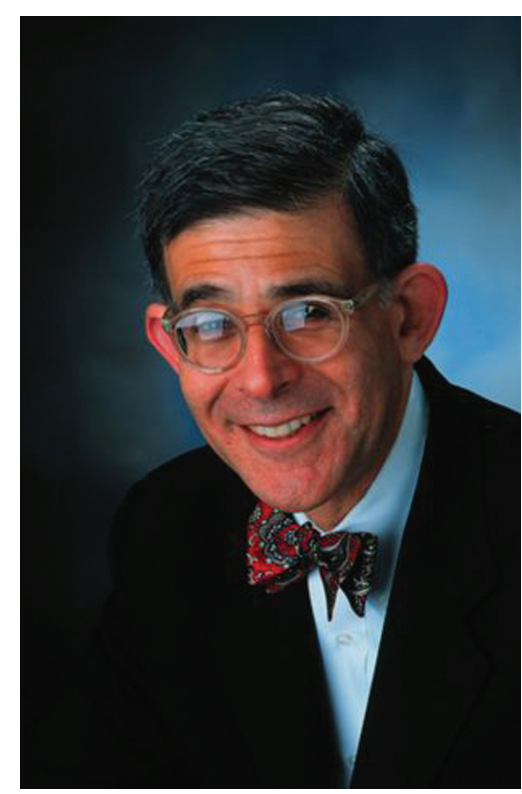

Merrill J. Egorin 1948-2010
His laboratory was always a fun place to visit. He approached the world with joy and his laboratory was always filled with numerous gas and liquid chromatographs, frogs made out of every material imaginable and of nearly every color, and a bevy of undergraduates, graduate students, and postdoctoral fellows. Merrill was the quintessential teacher. But his teaching was not limited to the laboratory because he loved the clinical arena as well and he was an outstanding clinician. When I was an intern, he would stop by my floor after teaching clinical skills to see if I was admitting any patients - and if I was, he would make the long trek with me to the emergency room to help me collect my new patient. He would regale us with stories of the days that the giants roamed the halls of the Osler Medical Service at Hopkins. Unlike many clinicianscientists who saw "service time" as a payback for being part of an academic medical center, Merrill saw it as one of the really fun and rewarding parts of his job. He was just as comfortable reading a gas chromatogram as he was talking to a family about the diagnosis of cancer. But he had passions outside of medicine as well-his Baltimore Orioles, the Hopkins lacrosse teams, and the Pittsburgh Steelers, Penguins and Pirates.

Merrill Egorin died on August 7, 2010, at the age of 62, $51 / 2$ years after being diagnosed with multiple myeloma. $\mathrm{He}$ will be remembered as a gifted world-wide for his expertise in cancer drug discovery, he often had to develop the methodologies for measuring the metabolism and pharmacokinetics of these new drugs in his own laboratory before he developed rational treatment strategies in animal models. Only then was he able to transition these novel compounds into the clinical arena in early Phase I studies where he evaluated whether the concepts developed in animal models held true in humans. He spent his life doing what many clinician-scientists dream of - taking a chemical from the test tube to the patient. But one goal was tantamount - to see to it that anticancer drugs were administered to patients in the safest and most effective way and with the lowest risk of side effects. researcher, a dedicated physician, and a passionate mentor. $\mathrm{He}$ is survived by his wife of 41 years, Karen Kantor Egorin, his son Noah, his daughter Melanie, and his sister, Sara Egorin-Hooper, and four grandchildren.

Kenneth L. Baughman was born and raised in Kansas City, Missouri. After attending the University of Missouri, where he earned his bachelor's and medical degrees, Ken went to Hopkins for his internship and residency. He and Merrill Egorin crossed paths for the first time during their residency-and clearly the Osler house staff left an indelible mark on both. Ken left Hopkins after residency to pursue a fellowship in cardiology at the Massachusetts General Hospital, but then returned to Hopkins as Assistant Chief 
of Service. He became the first "heart failure and transplant" doctor at Hopkins and later became Chief of the Division of Cardiology. He left Hopkins in 2002 when he was recruited to become the Director of Advanced Heart Disease at the Brigham and Women's Hospital in Boston.

Ken was the consummate clinician. He was caring, compassionate, and had boundless zeal for his work. He was extraordinarily skilled and dedicated to clinical excellence. Watching him examine a patient's cardiovascular system was like watching Yo-Yo Ma play the cello or Isaac Stern play the violin-he was a maestro. He taught using the Socratic method and challenged residents and students alike to do their best. Woe to the student who had not checked the serum potassium or the resident who had not viewed the imaging studies themselves. His gruff exterior and dry sense of humor masked a heart of gold. He was a role model for students, residents, and fellows and his dedication to the practice of medicine was palpable and infectious. Like many of those who trained under Ken, when faced with a difficult clinical situation, I ask myself, "What would Ken do?"

While translational medicine is often viewed as a benchto-bedside science-Ken approached the field from the bedside to the bench. In the early 1990s, he became intrigued by the concept that if we looked hard enough we could identify a causative-and potentially treatable-factor in patients who were diagnosed as having idiopathic dilated cardiomyopathy. In particular, he was fascinated by the concept that some patients with dilated cardiomyopathy had an inflammatory event in the myocardium referred to as myocarditis. Over the next 2 decades, he and his collaborators made seminal discoveries regarding the etiology of cardiomyopathy including the prevalence and etiology of idiopathic dilated cardiomyopathy, the ability of the HIV virus to infect the myocardium, the role of the endomyocardial biopsy in evaluating patients with new onset heart failure, the pathobiology of hypersensitivity myocarditis, and the unique aspects of giant cell myocarditis. He published the most comprehensive studies of patients with peripartum and postpartum cardiomyopathy as well as an exhaustive long-term follow-up of patients with idiopathic dilated cardiomyopathy. He reached out to collaborators in basic science, epidemiology, endocrinology, and other clinical sciences to optimize his ability to link the bedside with the bench and translate his observations into improved care for patients.

Like Merrill, Ken had three passions in life: his family, the practice of medicine, and athletics. He did few things without dedication-indeed he was a committed athlete who participated in marathons and triathlons. In October 2009, he placed first in his age category at a triathlon in the Adirondacks. But when I last saw him at a meeting in the fall of 2009, he only wanted to talk about his grandchildren and to hear how my own family was doing. On November 20, 2009, at the age of 63, Ken was killed when struck by a car while running in the morning before he was to attend the Annual Scientific Sessions of the American Heart Association in Orlando, Florida. He is survived by his wife Cheryl, their two sons, Mathew and Christopher, and four grandchildren.

Both Merrill and Ken brought enormous energy, enthusiasm, and skill to the field of translational medicine. They came to the translational sciences from two very different approaches-one as a physician-scientist and the other as a clinician-investigator. Both bridged the chasms that separate clinical investigation from basic science and both were committed clinicians who were dedicated to patient care and to the education of the next generation of physicians. They were both taken from us far too soon. They will be remembered by all of those they taught and cared for and hopefully the story of their careers can serve as guideposts for the trainees who will be the translational investigators of the future-a most fitting tribute to their memory. CTS 